\title{
Value Evaluation Research of Node Enterprise in the Energy Service Industry Value Network
}

\author{
Jun Dong, Xu Li ${ }^{*}$, Dongran Liu, Xu Sun \\ School of Economics and Management, North China Electric Power University, Beijing, China \\ Email address: \\ dongjun624@126.com (Jun Dong), m13051612801@163.com (Xu Li), liudongran@163.com (Dongran Liu), \\ 1551517314@qq.com (Xu Sun) \\ *Corresponding author
}

To cite this article:

Jun Dong, Xu Li, Dongran Liu, Xu Sun. Value Evaluation Research of Node Enterprise in the Energy Service Industry Value Network. Journal of Electrical and Electronic Engineering. Vol. 5, No. 3, 2017, pp. 92-97. doi: 10.11648/j.jeee.20170503.12

Received: April 13, 2017; Accepted: April 21, 2017; Published: June 7, 2017

\begin{abstract}
Energy service industry is an emerging industry which involves multi-subject, multi-product, multi-technology and multi-value, and is a complicated network system. The node enterprises in the system are connected with each other and the value added with the transmission which contributes to the value network. Value network is a new effective organization and management form of serving product supply chain, and it can increase the value of the serving products. In the value network of the energy service industry, the evaluation of the node enterprises' value creation is helpful for the enterprises to make strategic decision and helps the enterprises to create more value. In this paper, we take the energy service companies as the main research object and establish the index system of value evaluation. Besides, the fuzzy comprehensive evaluation method is used to evaluate the relevant factors, and the feasibility and effectiveness of the evaluation system are verified by examples.
\end{abstract}

Keywords: Value Network, Energy Service Companies, Value Evaluation

\section{Introduction}

Energy service industry is an emerging industry which involves multi-subject, multi-product, multi-technology and multi-value, and is a complicated network system. The main subject of Energy Services Company (Hereinafter referred to as ESCO) includes Energy Service Companies, energy using companies, financial institutions, equipment suppliers, design organizations, construction units, third party certification subjects and government regulators, and etc. The main subjects are connected with each other, and they can provide energy efficiency services with a variety of energy-saving technologies, financing tools and a variety of business models. Besides the creation of direct economic benefits, they can also reduce greenhouse gas emissions, reduce environmental pollution, increase employment opportunities, energy security and resource conservation and other indirect benefits. ESCO can provide a series of services including energy audit, design, procurement, monitoring, construction, training, operation and maintenance, management and so on. ESCO sign the service contract with users who are willing to do energy-saving reconstructions and related energy managements and get the benefits after the project implemented. The industries involved almost all manufacturing, institutions and other public institutions.

With the development of the Internet and information technology, fierce competition in the market makes enterprises to transform the traditional supply chain into value network to meet the growing needs of customers. Value network, a new theory different from the traditional value chain, has the following characteristics:

(1). Center on the customers' demands. Producing activities of the enterprises are based on the customers' actual demand and focus on how to maximize the value of the customer.

(2). Highly collaborative. The enterprises in the network focus on the joint efficiency of the members. Therefore, enterprises should take full advantage of the ability of partners, including embedded and outsourcing is the main means of enterprise operations in value network.

(3). Quick reaction. Information technology enhances the communication between the network members, and can responds to market demand in a timely and effective manner.

(4). Low-cost. Although the cost of information technology 
in the enterprise has increased, the reduction in transaction costs caused by information technology for the enterprise can offset the increased costs of infrastructure construction. Overall, the cost of the business is declining.

Value network is a new way for enterprises to gain competitive advantage. It is also a new way to add value to the enterprise. This way can improve the operational design to the macro level and contribute to the healthy development of industrial activities. The node enterprises in the energy service industry make up value network, through integrating the links and recourses in the network, it can help enterprises reduce unnecessary links between related enterprises, reduce transaction costs, and improve the relationship between suppliers and customers, avoid zero-game, achieve win-win results. Under the condition of value network, it is worthy to pay attention to the benefit of the enterprises in the energy service industry by means of the value network, this need to evaluate the benefits of the enterprises in the value network to help the enterprises make strategic decisions on the relevant value activities. Literature [1] points out the trend of the development of the energy service companies is cancelling subsidies, privatization and internationalization competition. Literature [2] studies the policy background and current situation of the development of the European energy- service industry, putting forward the long-term strategy to promote the development of it. Literature [3] introduces the concept of business model to the energy service industry and points out the main internal and external obstacles which impact the development of energy service industry. Literature [4] combs the research results of energy service industry at home and abroad, pointing out that the existing research is lack of economic theory and effective coordination of energy service clients as well as contractors operating activities are the core issues of industry development. Literature [5] analyzes the factors influencing the core competitiveness of energy service industry and studies the drive to the healthy development of the industrial resources optimization integration model.

Literature [6] introduces the theory of the dynamic alliance to energy-saving benefit sharing mechanism, uses fuzzy comprehensive evaluation method to determine the risk coefficient of each participation main body and establishes the benefit sharing model between the ESCO and the customer.

For the research of value network model, Literature [7] points out that the value network emphasizes on innovative. Information becomes the main characters and directly participates in value creation. Literature [8] considers that the enterprise value network has five basic competing advantage effects which are internet economy, economies of scale, risk versus, viscous effect and speed effect. About the constitution of the value network, Literature [9] thinks that value network is the objective existence. It consists of utility system, resources selection, rules and regulations, contact information, market pattern and system of value activities and other factors. Literature [10] builds a value network model in view of the service ecosystem under the business environment and makes a simple application.

\section{Energy Services Industry Value Network}

Energy service industry in China is still an emerging industries. And its development is still not perfect, the overall structure of the industry chain is relatively simple either. The two sides are mainly engaged in energy efficiency services enterprises and energy units or enterprises. The exchange of products is energy efficiency services. ESCO and energy using units or enterprises respectively are the supplier and the demander of energy efficiency services. So that a simple industrial chain is formed. The upstream suppliers of energy efficiency services companies mainly include various energy efficiency equipment manufacturing enterprises, energy efficiency products manufacturing enterprises, energy efficiency technology research centers and energy efficiency investment institutions, which provide energy equipment services, technology, funds, products, etc. Upstream suppliers are not involved in energy efficiency services transactions directly, they only provide energy using enterprises or units with energy efficient equipment, technology, products and so on in the case of the energy using units doing their energy-saving transformation themselves. In the case of energy efficiency services outsourced to ESCO, the energy using enterprises provide energy efficient equipment, technology, funds, products, etc. for ESCO, at the same time, ESCO provide energy services for energy companies or units. The middle of the industrial chain, all kinds of ESCO, in the case of energy-efficient service outsources to the ESCO, they use the energy-efficient equipment, technology, funds and products provided by upstream suppliers and mainly by using contract energy management (hereinafter referred to as EMC) Mechanism, through the comprehensive application of behavior energy-saving, equipment energy-saving, management energy conservation and technology energy-saving, to provide energy using enterprises with energy-efficient services in order to reduce the energy consumption of energy companies. In energy efficiency service transactions, ESCO is the supplier of energy efficiency services. Downstream users are all kinds of energy companies, mainly are the three major energy-consuming industries, that is, industrial enterprises, construction industry and transportation industry in China. Energy companies can purchase energy efficiency equipment, products and technologies from suppliers such as energy efficiency equipment manufacturing enterprises, energy efficiency products manufacturing enterprises, energy efficiency technology research centers, etc., and can also outsource energy-saving services to ESCO, which provides a full range of energy-saving transformation in return. In the case of energy-efficient services outsourced to ESCO, energy-efficient services are available from ESCO's demand side for energy efficiency services.

ESCO and upstream and downstream enterprises together constitute the energy service industry chain. With the development of the Internet and information technology, fierce competition in the market makes enterprises to 
transform the traditional value chain into a value network to meet the growing needs of customers. In the energy service industry, energy service companies are informed of the needs of enterprises through the network platform and other means of information. Due to the energy-using companies cannot complete energy-saving requirements with their own abilities, they sent a service request to the energy services company and cooperate in the form of energy management contract (EMC). So that energy-saving work outsourced to the energy services company. Energy service companies stimulate the production of periphery suppliers in accordance with the individual characteristics of energy companies. With the motivation of actual needs of enterprises and the guarantee of information technology, energy companies, energy services companies and their peripheral suppliers, information and capital both flow in the dynamic network of value networks. Energy services enterprises need to train personnel related to energy-using enterprises when they carry out contractual energy management. The update of energy efficiency devices and the purchase of energy efficiency products can be achieved directly through the network platform by energy-using enterprises after the project is delivered.

Value network emphasizes on customer-centric and regards customer demand as a driving force for the value of the network. Therefore, energy-using enterprises is in the core of the entire energy service industrial value network, and the energy services companies provide core products and service as the middle of the network. And related non-core enterprises which provide the services of energy efficiency are in the outer of the value network. The inner and outer layers establish interconnection through the information network. Energy service enterprises in the value of the network also established a certain connection relationship. The value flows dynamically in the connected network which creates a dynamic value network for the energy services industry. As shown in Figure 1.

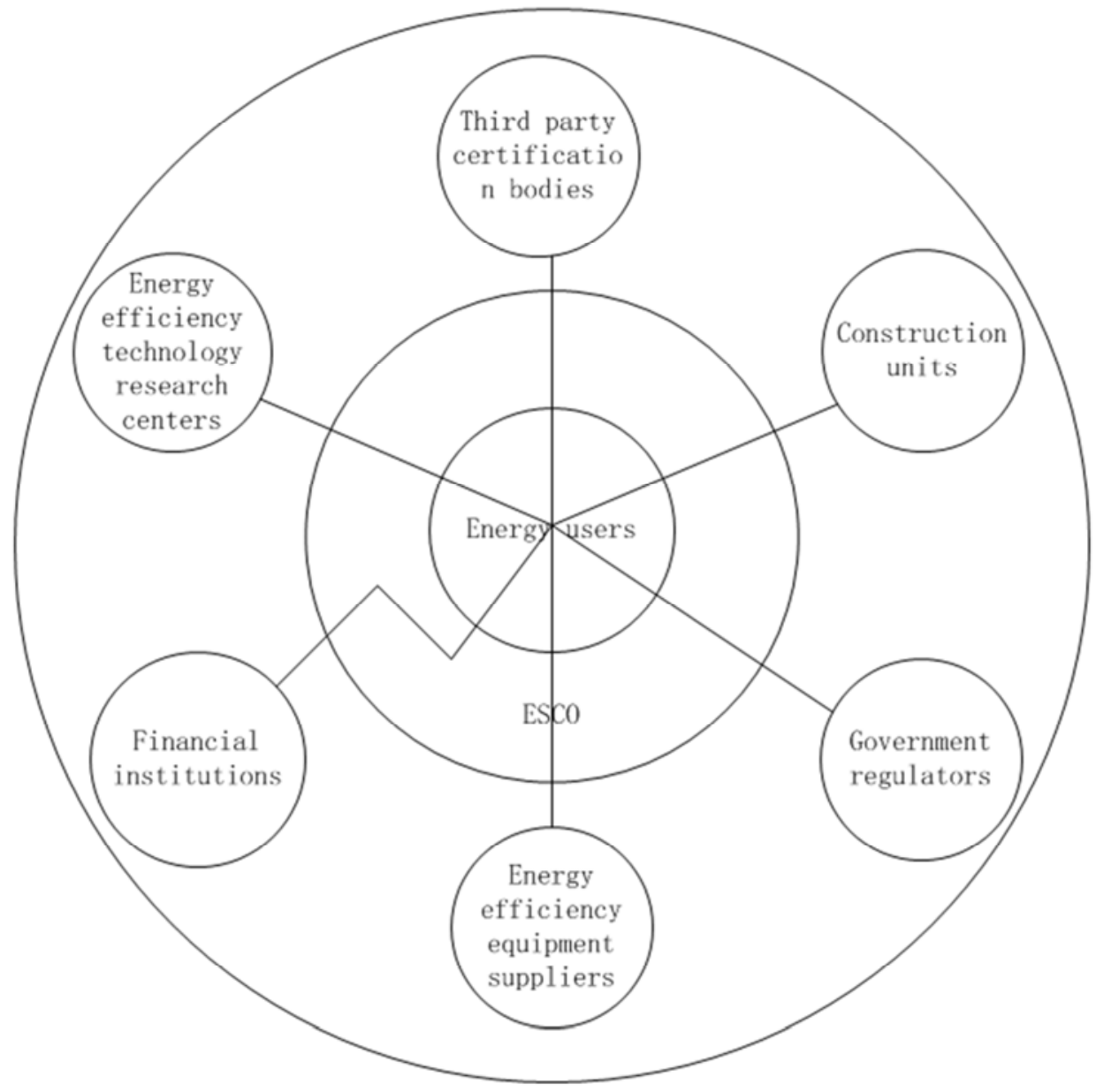

Figure 1. Dynamic value network of energy services industry.

\section{The Establishment of Node Enterprises' Evaluation Index}

The value network is the carrier of the value creation driven by the symbiosis between the core business and the node enterprise. The value creation of the node enterprise depends largely on its coordination with other nodes in the industry chain. The node enterprises promote the coordinated operation of the nodes in the value network through the integration of the value network resources, and these long-term stable cooperative contract arrangements bring the scale economy and scope economy to the core enterprises. In addition, the sharing of information and other resources makes the enterprise found 
costs, bargaining costs, decision-making costs, control costs, implementation costs and other transaction costs dropped significantly and achieves the value of the creation. In the energy service industry, it usually takes the ESCO as a research object for value evaluation, which mainly includes the coordination degree between ESCO and the service providers, coordination degree between the ESCO and the energy unit and the energy service industry network effects.

The coordination degree between ESCO and the service providers can be evaluated from the four indicators, those are, on time delivery rate of energy efficiency service provider (Supplier on time delivery rate $=$ number of on-time delivery / time of total delivery), quality of energy efficiency service related equipment, energy service provider's after-sales service and number of energy efficiency service providers. Coordination degree of ESCO and energy-using units can only be evaluated by customer satisfaction, customer loyalty, energy services market share and Demand value coefficient of customer demand. The value nets with high quality of network effect has given the ESCOs a certain economies of scale, scope effects, information and real-time sharing, and corresponding low transaction costs and inventories. In this paper, the input-output ratio and unit product cost are used to evaluate the economies of scale, and the economic effect is evaluated by the cost of production and sales. The value of transaction cost is used to evaluate the value creation effect of transaction cost savings, and the exchange rate is used to evaluate the information exchange degree.

Table 1. Energy service enterprise value network evaluation index system.

Primary index
Coordination degree between energy service
companies and service providers
Coordination degree between energy service
companies with energy units

Energy Service Enterprise Value Network Evaluation Index System

Secondary index
on time delivery of supplier
Energy efficiency equipment quality
Energy efficiency equipment follow-up services
Number of suppliers
Satisfaction of energy-using companies
Loyalty of energy-using companies
Efficiency of energy saving
Share of energy efficiency market
Value Coefficient of users' demand
stock-sales ratio
operating cost
transaction cost
cost per unit product
input-output ratio

\section{Evaluation Method of Node Enterprise Value Added}

(1) Determination of the weight of the indicator

In this paper, AHP is used to determine the weight of the index. AHP method is composed of the relative proportion of indicators between the judgment matrixes, by solving the maximum eigenvalue and its corresponding eigenvector, derived the relative proportion of the respective indicators.

First of all, based on the value of the enterprise to establish the judgment matrix, the judgment matrix is mainly based on data, expert opinions and the relative importance of understanding of indicators by analysts, which are given after the balance. And the general method is nine scale engraving. The degree is described in the table.

Table 2. Scale description of nine scale engraving method.

\begin{tabular}{ll}
\hline Scale & Implication \\
\hline & Compared with the two elements: \\
3 & The same importance; \\
5 & The former is more important than the latter slightly; \\
7 & The former is more important than the latte obviously; \\
9 & The former is more important than the latter intensively; \\
$2,4,6,8$ & The former is important than the latter extremely. \\
Reciprocal & \begin{tabular}{l} 
The intermediate value of the adjacent judgment \\
Importance scale of former element's importance than the \\
\hline
\end{tabular}
\end{tabular}

Judgment of the same level of indicators relative to the upper level of the importance of indicators can be used Delphi method, the establishment of the judgment matrix after the consistency test, in the test process using the consistency index formula.

$$
\begin{aligned}
& \text { C.I. }=\frac{\lambda_{\text {max }}-m}{m-1} \\
& \text { R.I. }=\frac{\lambda_{\text {max }}^{\prime}-m}{m-1}
\end{aligned}
$$

To determine the weight of the indicator

By using the product root method, the elements of the judgment matrix are normalized

$$
b_{i}=\left(\prod_{j=1}^{m} a_{i j}\right)^{\frac{1}{m}}
$$

The normalization matrix of each row is added by column, and the whole column vector is normalized, and the normalized relative importance of the element relative to the upper layer criterion.

$$
w_{j}=\frac{b_{j}}{\sum_{k=1}^{m} b_{k}}
$$


In this way, the evaluation index is calculated, and the weights of the indicators at all levels relative to the previous level are given, and the weight of the lowest level relative to the total evaluation index is obtained.

(2) Fuzzy comprehensive evaluation

Fuzzy comprehensive evaluation is the application of fuzzy set theory, through the evaluation of the subject of single factor evaluation, and then consider the weight of each factor and finally give a comprehensive evaluation results.

Set the index set

$\mathrm{U}=\left\{\mathrm{u}_{1}, \mathrm{u}_{2}, \mathrm{u}_{3}\right\}=\{$ Coordination degree between energy service companies and service providers,

Coordination degree between energy service companies with energy units,

Energy service industry network effect\}

$$
\begin{aligned}
& \mathrm{U}_{1}=\left\{\mathrm{u}_{11}, \mathrm{u}_{12}, \mathrm{u}_{13}, \mathrm{u}_{14}\right\}=\{\text { on time delivery of supplier, } \\
& \text { Energy efficiency equipment quality, } \\
& \text { Energy efficiency equipment follow-up services, Number of suppliers }\}
\end{aligned}
$$

And so on, and then according to the weight of the analytic hierarchy process to determine the weight set.

Univariate evaluations require $\mathrm{N}$ experts to evaluate individual factors to determine the membership of each factor for each rating level. This paper intends to use the degree of impact to be assessed, the assessment criteria are divided into excellent, good, general, poor, poor five grades. Table 3 is an evaluation form filled out by an expert.

Table 3. Expert evaluation form.

\begin{tabular}{lllllll}
\hline \multirow{2}{*}{ Factors } & \multicolumn{6}{l}{ Evaluations } \\
\cline { 2 - 7 } & $v_{1}$ & $v_{2}$ & $v_{3}$ & $v_{4}$ & $\ldots$ & $v_{m}$ \\
\hline$U_{1}$ & $x_{11}^{(k)}$ & $x_{12}^{(k)}$ & $x_{13}^{(k)}$ & $x_{14}^{(k)}$ & $\ldots$ & $x_{1 m}^{(k)}$ \\
$\ldots$ & $\ldots$ & $\ldots$ & $\ldots$ & $\ldots$ & $\ldots$ & $\ldots$ \\
$U_{n}$ & $x_{n 1}^{(k)}$ & $x_{n 2}^{(k)}$ & $x_{n 3}^{(k)}$ & $x_{n 4}^{(k)}$ & $\ldots$ & $x_{n m}^{(k)}$ \\
\hline
\end{tabular}

$x_{i j}^{(k)}$ is the membership of evaluation object according to the factor $U_{i}$ and obtained judgment $v_{j}$ by expert No. k. And then evaluation matrix can be obtained by the overall membership

$$
R=\left(r_{i j}\right)=\left[\begin{array}{cccc}
r_{11} & r_{12} & \cdots & r_{1 m} \\
r_{21} & r_{22} & \cdots & r_{2 m} \\
\cdots & \cdots & \cdots & \cdots \\
r_{n 1} & r_{n 2} & \cdots & r_{n m}
\end{array}\right] r_{i j} \in[0,1]
$$

$r_{i j}$ is the membership of evaluation object according to the factor $U_{i}$ and obtained judgment $v_{j}$ by the evaluation of all the experts.

When the weight set $\mathrm{A}$ and the single factor evaluation matrix R are known, the fuzzy transformation can be used for the comprehensive evaluation. Fuzzy comprehensive evaluation model as shown:

$$
B=\left(b_{1}, b_{2}, \cdots, b_{m}\right)=A o R=\left(a_{1}, a_{2}, \cdots, a_{n}\right) o\left[\begin{array}{cccc}
r_{11} & r_{12} & \cdots & r_{1 n} \\
r_{21} & r_{22} & \cdots & r_{2 m} \\
\cdots & \cdots & \cdots & \cdots \\
r_{n 1} & r_{n 2} & \cdots & r_{n m}
\end{array}\right]
$$

Among them, $b_{j}$ is a comprehensive consideration of all factors affect the evaluation of objects belonging to the first $j$ of the membership of the degree of $v_{j}, B$ is a set of judgments $V$ on the fuzzy set. " $O$ " denotes a composite operator. The resulting $B$ represents the membership of the factor set $U$ for the comment set $V$. Then, according to the principle of maximum membership, the influence degree of the relevant influence factors of the node enterprises is determined to help the energy service enterprises to analyze the influence degree of the relevant value nodes in the value network.

\section{Empirical Analysis}

Shenzhen Latitude Energy Conservation Services Limited Company (Hereinafter collectively referred to as "Latitude Energy Saving") was established in 2009. It is the first structured energy services company in China, and it made the National Development and Reform Commission and the Ministry of Finance filing in 2011. The main business of the company includes: energy efficiency management solutions, energy efficiency management consulting, energy conservation investment, energy efficiency management technology research and development, which covering industrial energy efficiency management, building energy efficiency management and lighting energy efficiency management.

Through the research on the stakeholders of Shenzhen Latitude Energy Saving Service Company, the comparison of each index is carried out, and the scale of the index is given to the experts, and the scale value or score of each index relative 
to the other index is obtained. And then use the AHP level

of each indicator as shown in the table:

evaluation software to analyze the scale value, get the weight

Table 4. Primary Indicator Weights.

\begin{tabular}{llll}
\hline $\begin{array}{l}\text { Value network evaluation } \\
\text { of energy service industry }\end{array}$ & $\begin{array}{l}\text { Coordination between energy } \\
\text { service companies and suppliers }\end{array}$ & $\begin{array}{l}\text { Coordination degree of energy service } \\
\text { companies with energy-using units }\end{array}$ & $\begin{array}{l}\text { Value network effect of energy } \\
\text { service industry }\end{array}$ \\
\hline Weight value & 0.3842 & 0.3842 & 0.2316 \\
\hline
\end{tabular}

Table 5. Secondary Indicator Weights.

\begin{tabular}{|c|c|c|c|}
\hline \multirow{15}{*}{ The value of Energy service industry } & The secondary indicators & Third grade indicators & Weight value \\
\hline & \multirow{4}{*}{$\begin{array}{l}\text { Coordination degree between energy } \\
\text { service companies and suppliers }\end{array}$} & On time delivery rate of supplier & 0.3790 \\
\hline & & Quality of energy efficiency equipment & 0.4072 \\
\hline & & Follow-up services of energy efficiency equipment & 0.1227 \\
\hline & & Number of peripheral suppliers & 0.0911 \\
\hline & \multirow{5}{*}{$\begin{array}{l}\text { Coordination degree between energy } \\
\text { service companies and energy-using } \\
\text { units }\end{array}$} & Satisfaction of energy consumer & 0.2866 \\
\hline & & Loyalty of energy consumer & 0.1831 \\
\hline & & Energy efficiency market share & 0.2410 \\
\hline & & Energy efficiency & 0.2302 \\
\hline & & User Demand Value Coefficient & 0.0591 \\
\hline & \multirow{5}{*}{$\begin{array}{l}\text { Network effect of energy service } \\
\text { industry }\end{array}$} & Input-output ratio & 0.0872 \\
\hline & & Inventory rate & 0.4285 \\
\hline & & Unit product cost & 0.1515 \\
\hline & & Production and marketing costs & 0.2541 \\
\hline & & Transaction cost & 0.0786 \\
\hline
\end{tabular}

Calculate the results based on weight value

Through the experts on the secondary indicators of the score and the corresponding weight of each index multiplied to calculate the level of indicators of the criteria, and finally get the evaluation matrix. The specific results are as follows:

External coordination degree $\mathrm{F}=(0.2185,0.4927,0.2447$, $0.0441)$

Internal coordination degree $\mathrm{F}=(0.28061,0.32878,0.13885$, $0.15319,0.09856$ )

Industrial value network effect $\mathrm{F}=(0.29451,0.32395$, 0.24829, 0.09116, 0.04199)

Can finally get the value of energy service industry network $\mathrm{F}=(0.25996,0.39046,0.20486,0.09701,0.04753)$

For the value of the energy service company in the value network, the maximum of its matrix is 0.39064 , According to the commentary, it is clear that the value of the value network is more prominent, mainly because the coordination between company and other nodes of the enterprise is good, energy efficiency equipment quality and after-sales service is better, and it has a certain customer base. However, it should also be noted that the value of the industrial network effect in the value network is not obvious. Enterprises should refine the cooperation network with customers and suppliers in the future business decisions, play the network effect, reduce costs and enhance the industrial value.

\section{References}

[1] Edward Vine. An international survey of the energy service company (ESCO) industry [J]. Energy Policy, 2005, (33): 691704 .
[2] Paolo Bertoldia, Silvia Rezessyb, Edward Vinec. Energy service companies in European countries: Current status and a strategy to foster their development [J]. Energy Policy, 2016, (34): 1818-1832.

[3] Satu Patari, Kirsi Sink konen. Energy Service Companies and Energy Performance Contracting: is there a need to renew the business model? Insights from a Delphi study [J]. Journal of Cleaner Production, 2013: 1-8.

[4] Huang Jiatao, Zhang Depeng, Lin Hong ling, research overview of energy-saving service industry [J], Journal of Management, 2012, 25 (3): 73-76 (In Chinese).

[5] Wang Jingmin, Sun Yanfu, Kang Jun jie. Research on the driver model which promotesthe core competitiveness of energy-saving service industry [J]. Resources and Industry, 2014, 13 (3): 151-154. (In Chinese).

[6] Zhao Dan. The research of economic benefits of energy-saving projects evaluation and sharing mechanism [D]. North China Electric Power Universiy (Hebei), 2008. (In Chinese).

[7] Zhang Huimin, Jiao Zheng ming, Li Yun feng. Research overview of Value network theory [J]. China's e-commerce, 2011 (7): 305-306. (In Chinese).

[8] Zhou Xuan. Research on the competitive advantage of the enterprise value network [J]. Chinese Industrial Economy, 2015 (5): 112-118. (In Chinese).

[9] Liu Desheng. The competitive advantage of multinational companies in perspective of value network. [J]. Foreign Economic and Trade, 2007 (2): 57-58. (In Chinese).

[10] Li F, Tian C, Cao R Z, et al. Value network model for service ecosystem in business environment $[\mathrm{C}] / /$ Network Operations and Management Symposium, 2008. NOMS 2008. IEEE. IEEE, 2008: 955-958. (In Chinese). 